\title{
Comparison of visual census and high definition video transects for monitoring coral reef fish assemblages
}

\author{
Dominique Pelletier ${ }^{\mathrm{a}},{ }^{*}$, Kévin Leleu $^{\mathrm{b}}$, Gérard Mou-Tham ${ }^{\mathrm{b}}$, Nicolas Guillemot ${ }^{\mathrm{b}}$ and Pascale Chabanet $^{\mathrm{c}}$ \\ a IRD-UR CoReUs/EMH IFREMER, BP A5, 98848 Nouméa Cedex, New Caledonia, France \\ ${ }^{\mathrm{b}}$ IRD-UR CoReUs/Centre IRD de Nouméa, Nouméa, New Caledonia, France \\ c IRD-UR CoReUs/IRD La Réunion, BP 172, 97492 Ste Clotilde Cedex, La Réunion, France \\ *Corresponding author : D. Pelletier, Tel.: +33 298224684, email address : dpellet@ifremer.fr
}

\begin{abstract}
:
Monitoring fish and underwater habitats, particularly in and around marine protected areas (MPAs) requires non-destructive observation methods. This is generally achieved by divers conducting underwater visual censuses (UVC), but video-based techniques are now being used more often to observe underwater macrofauna and habitats. A comparison of these two techniques is relevant with the development of high-definition (HD) video, which constitutes a substantial improvement over previously available video resolutions at limited extra cost. We conducted a paired observation experiment involving both HD video and UVC in an MPA located in the New Caledonian lagoon, which is a highly diversified coral reef ecosystem. We compared three techniques for counting fish along 50 $\mathrm{m} \times 4 \mathrm{~m}$ delineated strip transects: UVC and two video techniques in which the diver used either a straight trajectory (I-type transect) or a browsing one (S-type transect). The results showed that the proportion of fish that were not identified up to the species level did not exceed $3.3 \%$ in video observations versus $1.7 \%$ in UVC. The abundance and species richness were larger in UVC than in videos, and S-type transects detected more individuals and species than I-type transects. The average abundance and species richness observed by UVC were 1094 individuals and 69.7 species per transect respectively. In comparison with UVC, I-type and S-type video transects detected on average $56 \%$ and $61 \%$ of the abundance and $85 \%$ and $77 \%$ of the species richness seen by UVC respectively. Our results showed that, in comparison to UVC data recorded in situ, the post field analysis of HD video images provided representative observations of fish abundance and species diversity, although fewer species and individuals were detected.
\end{abstract}

The advantages and shortcomings of each observation technique for monitoring fish assemblages, particularly in an MPA are discussed. HD video appears to be a cost-effective technique in terms of the human resources and time needed for field implementation. Overall, this study suggests that HD video-based techniques constitute an interesting complement to UVC, or an alternative when these cannot be implemented.

Keywords: Fish assemblages; MPA monitoring; High-definition underwater video; Underwater visual censuses (UVC); Coral reefs 


\section{Introduction}

47 Coral reef ecosystems are characterized by their level of species diversity, which is among the highest of world's marine ecosystems (Connell 1978; Ray 1988). Recent reports on the condition of coral reefs warn of their ongoing

50 degradation (Wilkinson 2004). This situation requires the implementation of 51 management measures aimed at i) preserving the biodiversity of coral reef 52 ecosystems and ii) sustainable development of the activities that depend on 53 these ecosystems. Marine protected areas (MPAs) are a key management 54 instrument for achieving these two objectives, and quantitative targets have been set for a global network of MPAs in the coming years (Convention for 56 Biological Diversity (CBD), http://www.biodiv.org/defaults.html). With these 57 recommendations comes the obligation to establish monitoring programs to track the progress toward the achievement of biodiversity conservation, based on tools that do not disturb the ecosystem. Therefore, monitoring and 60 assessment of fish and their habitat in particular in and around highly protected 61 MPA require non-destructive observation methods. This is generally achieved 62 by underwater visual censuses (UVC) which have been successfully used for 63 years to estimate reef fish abundance or biomass in studies of population dynamics, ecology and management (e.g., Barans and Bortone, 1983;

65 Samoilys, 1997; Samoilys and Carlos 2000; Bortone et al., 2000). The 66 advantages and disadvantages of this method have been summarized in 67 several papers (Harmelin-Vivien et al. 1985; Harmelin-Vivien and Francour 68 1992; Cappo and Brown 1996; Samoilys 1997; Willis et al. 2000; Watson et al. 2005). For example, some "shy" or cryptic species are not accurately observed 
because they avoid the presence of the divers conducting the census (Kulbicki 1998; Watson et al. 1995, 2005; Stewart and Beukers 2000; Willis and Babcock 2000, Willis 2001).

UVC requires experienced divers that are trained for identifying species and estimating individual fish sizes. For the purpose of MPA monitoring, managers often prefer methods that do not require experienced divers and that can be implemented by MPA staff. In the last fifteen years, video-based techniques have become commonly used tools for observing underwater macrofauna and habitat, in particular for fish (Michalopoulos et al. 1992; Potts et al. 1987; Tipping 1994, Tessier et al. 2005, Watson et al. 2005). UVC and video techniques, whether remote or diver operated involve distinct costs in the field and in the laboratory. These can be compared using cost-benefits analyses, such as the study by Langlois et al. (2010) who compared two stereo-video techniques across tropical and temperate systems.

High definition (HD) video is a recent and substantial improvement over previously available resolutions at little extra cost, but it is still rarely used for underwater ecological observations compared to UVC. Harvey et al. (2010) found that a HD stereo-video system gave better precision and accuracy of length measures compared to a standard video system.

Here we do not intend to compare HD video with standard video because HD

90 video is becoming that standard in both consumer and professional video systems.

92 Therefore, we investigated the value of using HD video techniques versus

93 UVC for observing fish assemblages in a highly diversified coral reef ecosystem 
94 of the South Pacific. For this purpose, we conducted a paired observation experiment involving both video transects and UVC transects in an MPA located in the New Caledonian lagoon. Our interests were two-fold: i) to compare UVC and HD video, and ii) comparing rapid video transects versus longer video transects for the purpose of monitoring. Here, we report our findings from this experiment, and discuss the advantages and shortcomings of each observation technique for monitoring highly diversified fish assemblages such as those encountered at coral reefs and particularly in MPAs. Cost-effectiveness issues are also discussed.

\section{Methods}

105

\subsection{Observation protocol}

The study area was located in the Southwest Lagoon of New Caledonia,

108 South Pacific. The lagoon encompasses a network of marine reserves including 109 reefs and islets. Our experiment was conducted around Signal Island, which

110 has been protected from all fishing since 1989 (Fig. 1). Three sites located on

111 the reef were selected that correspond to habitats with distinct complexities in

112 shallow areas at a depth of 3 to $5 \mathrm{~m}$. Within each site, we delineated three $50 \mathrm{~m}$

113 long and $4 \mathrm{~m}$ wide transects using a measuring tape. For habitat analysis, five 114 segments of $10 \mathrm{~m} \times 4 \mathrm{~m}$ were delineated within each transect. In each transect, 115 we carried out both UVC and video observations. UVC were performed by 116 swimming slowly and pausing for fish identification and counting when needed.

117 For each UVC, all individual fish in the transect were identified and counted 
118 underwater, and their size was estimated. Two types of video observations

119 were conducted: i) where a diver swam through the transect in a straight line, at

120 a constant speed (ca. 0.2-0.3 m.s $\mathrm{s}^{-1}$ ) and elevation (ca. $1.5 \mathrm{~m}$ above the bottom),

121 the camera pointing at an approximate angle of $100^{\circ}$ with the water surface (I-

122 type transect); and ii) where the diver browsed inside the transect area in a

123 similar fashion to the diver conducting the UVC transect, at varying elevation,

124 speed, and angle and zooming when needed (S-type transect).

125 The elevation chosen for I-type transects enabled the wide angle of the 126 camera to capture the entire width of the transect. In browsing transects (S-

127 type) and in the UVC, the diver could look in any direction, stop and change 128 their elevation.

$129 \quad$ I-type transects lasted on average 4 min $30 \mathrm{~s}$, while S-type transects lasted 130 on average $10 \mathrm{~min}$ and UVC lasted between 45 and $60 \mathrm{~min}$. There were at least

$1315 \mathrm{~min}$ between any two successive observations. Observations were thus 132 considered as independent. We aimed at testing the effect of the transect type 133 (straight video, browsing video and UVC) as well as the effect of carrying out 134 the video observations before or after the UVC. For this purpose, we successively performed in each transect one video observation of each type, one UVC observation and then another video observation of each type. For the

137 pairs of video observations conducted either before or after the UVC, the order 138 of the video transect type was randomized. Therefore, our experimental design crossed three levels of "transect type" with two levels "before/after".

140 Video images were obtained using a HD Sony ${ }^{\mathrm{TM}}$ camera HDR-SR1 with an 141 integrated hard drive of 30 gigabytes enabling up to $4 \mathrm{hr}$ of HD images to be 
142 collected. The camera records a signal that follows the 1080i standard, i.e., with

143 a resolution of $1920 \times 1080$ pixels (Full HD), and that is saved on the internal

144 hard drive using the AVCHD $^{\text {TM }}$ format which is based on the MPEG-4

145 AVC/H.264 for image compression. The housing and lens resulted in an

146 approximate focal angle of $60^{\circ}$. No artificial light was used. Images were

147 analyzed on a 22' screen by the same fish expert that carried out the UVC,

148 using standard viewing software that enables slow view and zooming, such as

149 PowerDVD $^{1}$ or the Nero Suite ${ }^{2}$. All fish were identified and counted per species

150 and size class. Size classes were small, medium or large. Class boundaries

151 were defined by UVC divers to ensure that the size classes used for video were

152 consistent with UVC observations. Image analysis was conducted several

153 weeks after the field work so that the UVC observations did not influence the 154 analysis.

155 For each transect at each site, habitat was characterized from the images

156 using the medium-scale approach (MSA) described in Clua et al. (2006). For

157 each segment in each transect, the percent cover of biotic and abiotic 158 components was recorded. Ten categories were considered for the abiotic 159 components, and seven categories were defined for living hard coral (Table 1).

160 Algae and sponges were not recorded because they were scarce in the study 161 site. Values were then averaged over segments for each observation in a given 162 transect.

163 164

\footnotetext{
${ }_{1}^{1}$ PowerDVD (Version 9.0 Ultra). Cyberlink Corp. 2009.

${ }^{2}$ The Nero Suite (Version 9) Nero Ltd. 2009..
} 
166 We first tested the effects of conducting the video transects before or after

167 the UVC on the overall abundance and species richness per transect by fitting 168 two-way ANOVA models to video transect data. The models (one for species 169 richness and one for abundance) included a time (before or after) and transect 170 type (I-type and S-type) factors. The before/after effect was tested using a t171 test.

172 Next, we analyzed the abundance and species richness observed from UVC 173 counts and from the two types of video transects. The tests and comparisons 174 for this analysis were conducted by two-way ANOVA modeling of species 175 richness and abundance, considering the site (three levels: site 1, site 2 and 176 site 3), and transect type (three levels: UVC, I-type, and S-type). Using this 177 method, we could predict the mean abundance and species richness per 178 transect that can be expected to be observed by each observation technique, 179 namely UVC and I-type and S-type transects. Our results were interpreted 180 considering the differences in sites due to habitat, on the basis of the MSA 181 description of habitat. For this purpose, the percent values of biotic and abiotic 182 components of habitats were averaged over the transects of each site to 183 provide information for between-site comparisons.

184 In a third step, we investigated the differences in fish assemblages observed 185 from each observation technique. For each family, we first calculated the 186 number of species and the abundance per transect. Then for each transect 187 type, the overall means for both abundance per family and species number per 188 family across transects were computed by averaging the previous values over 
189 transects of a given type. For a number of families that were observed in both a 190 large proportion (more than $75 \%$ ) of video observations and in all UVC

191 observations, the abundance per family was modelled using a two-way ANOVA

192 involving the site and transect type factors. Differences due to transect type 193 could thus be statistically tested. For the other families, no test was carried out 194 because the number of zero observations was too high to enable quantitative 195 comparison.

\section{Results}

198

\subsection{Fish identification}

200 During the 36 video transects conducted, 37950 individual fish were 201 observed corresponding to 182 species from 35 families. A number of fish could 202 not be identified at the species level: 655 individuals were identified at the 203 genus level, 592 individuals were identified at the family level, and 28 204 individuals were not identified at all. Overall, only $3.3 \%$ of all observed fish were 205 not identified at the species level. Most fish that were identified at family level 206 only corresponded to juvenile individuals belonging mainly to Scaridae 207 (parrotfish) and Pomacentridae (damselfish) (80\% and $17 \%$ of individuals 208 identified at family, respectively). Similarly, most fish that were identified only at 209 the genus level were represented by Pomacentrus and Scarus $(67 \%$ and $26 \%$ 210 of individuals identified at genus level, respectively).

211 In the 9 UVC transects, 11,394 fish individuals were observed, corresponding 212 to 138 species from 29 families. Among these, all individuals were identified at 
213 the species level, except for $1.7 \%$ (200 ind.) that could only be identified at the

214 genus level, most of which belonged to damselfish (77 ind.), parrotfish (65 ind.)

215 and labrids (39 ind.).

3.2. Before/after UVC effect on video transects

218 For video observations, the difference in species richness or abundance due

219 to transect type was larger than that due to timing of the video transect (Fig. 2).

220 This was confirmed by three-way ANOVA fitted on these variables with site,

221 transect type and before/after factors. Though the model of species richness

222 was highly significant (adjusted $R^{2}=0.47, F(11,24)=3.81$ with $p=0.003$ ), the

223 transect type effect was the only significant effect $\left(p=1.7 .10^{-5}\right)$ and the

224 before/after effect was far from being significant $(p=0.65)$. For abundance, the

225 model with three factors was not found to be significant overall, but the model

226 with only the transect type and the before/after factors was significant (adjusted

$227 \mathrm{R}^{2}=0.2891, \mathrm{~F}(3,32)=5.7$ with $\left.\mathrm{p}=0.003\right)$. In the latter model, the before/after

228 effect was not significant $(p=0.79)$ and the transect type effect was the only

229 significant effect $(p=0.00025)$. Therefore, conducting the video observation

230 before or after the UVC was found to have no significant effect on the overall

231 abundance and species richness that were detected per transect. We also

232 compared the abundance per family observed before and after for a given

233 transect type. The correlation coefficient between these two abundance values

234 was $0.998\left(p<2.2 .10^{-16}\right)$. Two ANOVA models including the transect type, site,

235 family, and before/after factors respectively fitted to the abundance and species

236 richness per family confirmed that the before/after factor was not significant and 
237 did not interfere with the other effects. Non-identified individuals were excluded 238 from the latter models, as well as Pomacentridae, because the distribution of 239 corresponding data did not meet model assumptions when they were included.

240 Because the before/after effect was found not to be significant, it was not 241 considered in the rest of the analysis. transect.

At each site (S1, S2, S3), the mean species richness per transect observed for each transect type was, respectively, $(38.7,38.5,35.8)$ for I-type, (54.7, 45.8, 45.2) for S-type, and $(69.7,60.3,63.7)$ for UVC transects. Mean abundances per transect observed at each site were, respectively, $(612,728$, 704) for I-type, $(932,901,1008)$ for S-type, and $(1094,1570,1134)$ for UVC. The observed abundances and species richness were larger with UVC than with video, and S-type transects detected more individuals and species than Itype transects (Fig. 3).

We fitted a two-way ANOVA with transect type and site factors to both the 254 overall abundance and species richness per transect. For species richness, the 255 model was valid and highly significant (adjusted $R^{2}=0.77, F(8,36)=19.2$ with $p<7.10^{-11}$ ), and only the effects of the transect type and site were significant $\left(p<4.9 .10^{-13}\right.$ and $p<9.10^{-3}$, respectively). For the abundance and species richness, the adjusted $R^{2}$ were 0.58 and 0.62 , respectively; the $F(8,36)$ statistics

259 were $8.5\left(p<2.1 .10^{-6}\right)$ and $9.95\left(p<3.5 .10^{-7}\right)$, and the only significant effect found 260 was due to transect type $\left(p<5.9 .10^{-8}\right.$ and $p<2.4 .10^{-9}$, respectively). In both 
261 cases, the interaction between site and transect type was not significant,

262 indicating that differences between the transect types did not depend on the 263 site

264 This model was used to predict the species richness, abundance and number

265 of families per transect that can be detected by each technique (Table 2). The 266 predicted average abundance and species richness obtained from UVC were 2671094 individuals and 69.7 species per transect, respectively. The predictions of 268 abundance and species richness for I-type video transects were $56 \%$ and $61 \%$, 269 respectively, of the abundance and species richness predicted for UVC, while 270 for S-type video transects, they were $85 \%$ and $77 \%$ respectively of the 271 predictions for UVC.

272 From UVC, the species richness appeared to be higher at site 1 than at the 273 other sites, and the overall abundance was higher at site 2 than at the other 274 sites (Fig. 3). Between-site differences in abundance and species richness may 275 be attributed to differences in coral reef habitats (Table 1). Site 1 was 276 characterized by a larger cover of living coral which were mostly massive coral, 277 while site 2 exhibited much more debris cover than the other two sites (40\% of 278 debris versus $\sim 13 \%$ at the other sites), with more branched coral than massive 279 coral ( $63 \%$ of branched coral versus $26 \%$ and $50 \%$ at the other sites), and 280 some table coral, causing this site to have a lower habitat rugosity. Site 3 was 281 intermediate in terms of rugosity; it had more sand and dead coral than the 282 other sites, but also contained a large amount of branched coral and some 283 massive coral. 


\subsection{Results per family}

Twenty-nine families were observed in the 9 UVC and 35 in the 36 video

287 observations (Table 3). In the rest of this paper, only S-type video observations

288 will be compared to UVC because they provide more complete observations 289 than I-type transects. Because the number of S-type video observations conducted was twice that of the number of UVC, the total species richness and abundances cannot be directly compared. In terms of occurrences,

292 Pomacentridae, Labridae, Scaridae, Chaetodontidae, Acanthuridae, 293 Pomacanthidae, Nemipteridae, Mullidae, and Blennidae, were observed in 294 either all or more than $89 \%$ of video observations. Serranidae, Gobiidae, 295 Lutjanidae and Balistidae and Synodontidae were seen in more than half of the video observations. The other families were seen less often. Each of these families was seen in all UVC, except for Balistidae, Synodontidae, Gobiidae and Lutjanidae.

299 For each family, the mean abundance per transect and mean species 300 richness per family were computed by averaging values computed at the transect level, which mitigates the effect of differences in transect numbers between techniques. The results indicated that the mean number of species per

303 transect that were detected from UVC was larger than from the videos, except 304 for Scaridae, Nemipteridae, Aulostomidae and Lutjanidae (Fig. 4). However, the number of species detected by video transects is relatively large and is not considerably smaller than the number detected by UVC, particularly for frequent

307 families such as Pomacentridae, Pomacanthidae, Scaridae, Labridae, 308 Chaetodontidae Acanthuridae and Blennidae. For 21 families out of 35, the 
309 mean abundance per transect was larger in UVC than in videos, though this

310 difference was not large for 8 of these families. The reverse was true for 2

311 families, and abundances were similar for 4 families. For each family that was

312 encountered in a sufficient number of video transects (more than $75 \%$ ) and in

313 all UVC transects (Table 4), a two-way ANOVA with transect type and site

314 factors was fitted to the family abundance per transect. For all of the models

315 presented, the fits were good, and the residuals conformed well to linear model

316 assumptions. The interaction between the site and transect type was not

317 significant (except for Pomacentridae), which indicates that transect types

318 compared similarly across habitats, i.e., the comparison did not depend upon

319 fish abundance. From these models, the abundance predicted by UVC was

320 always larger than that predicted by video (Table 4). The predicted abundances

321 were very similar for Pomacentridae and Nemipteridae, with video observations

322 detecting 92\% and 94\%, respectively, of the UVC-detected abundance. For

323 Chaetodontidae, Acanthuridae and Blennidae, UVC predictions of abundance

324 were considerably larger than those from video, with video detecting $72 \%, 66 \%$

325 and 54\%, respectively, of the UVC-detected abundance. For Scaridae and

326 Mullidae, the abundance predicted by UVC exceeds by far that predicted from

327 video, with video detecting $43 \%$ and $36 \%$, respectively, of the UVC-detected

328 abundance. For families with an occurrence in between 7 and 11 video

329 transects (40 and $60 \%$ of video transects, Table 3), no model was fitted, but the

330 UVC abundance was larger than the video abundance for Synodontidae,

331 Tetraodontidae, Gobiidae, Lutjanidae and Penguipedidae, and the reverse was

332 true for Balistidae. For families rarely encountered (in less than $40 \%$ of video 
333 transects, Table 3), our results should be interpreted with caution. Note that

334 Lutjanidae were seen much more often in video transects than in UVC, but the mean abundance per transect was larger in UVC due to a school of individuals

336 being encountered.

\section{Discussion}

4.1. Observations of the fish assemblage according to the technique used

Abundance and species richness were larger in UVC than in video

observations, but the fraction of the fish assemblage that can be detected from video images is representative overall. The comparison between these techniques is discussed here with regard to species identification and fish detection taking into account fish abundance and habitat complexity.

348 First, the ability to identify species is one of the most frequent concerns

349 raised about video techniques. It is often assumed that fish identification is 350 difficult in 2-dimensional images. However, in the present study, the proportion

351 of fish that were not identified up to the species level did not exceed $3.3 \%$ in 352 videos versus $1.7 \%$ in UVC. This lower proportion for UVC may be due to the level of expertise of the divers, and the fact that these can pay more attention in

354 the field for species that are difficult to identify. The almost equally low 355 proportion of species identified in videos may be explained by the use of HD cameras and to a lesser extent to the large screen used for image analysis. 
357 Additionally, for S-type transects, the camera was filming as close to the fish as

358 the diver during UVC, thus making image analysis easier.

359 An advantage of video transects was that images could be re-analysed and

360 observers could spend more time identifying an individual from the guide books and differentiate between species, thereby allowing for more individuals to be identified at species level.

The second possible difference in the data obtained by these observation methods concerns the detection of fish species and fish individuals. Overall, our

365 findings indicate a larger number of fish observed in UVC compared to video, 366 although the results depend on fish families. This finding may be explained by 367 the fact that UVC lasted on average 3 to 4 times as long as S-type video transects. Thus more time was available to encounter individual fish underwater. Overall, the difference between UVC and video is larger for the abundance than for the species number. There are two possible hypotheses to explain this. First, in 2-dimensional images it is more difficult to estimate the number of individuals within a school than from direct underwater viewing, which might lead to lower abundance estimates from video compared to UVC. Second, assigning an individual to a given species from the video screen might lead to the distinction of more species if the identification is done with the help

376 of a book. In addition, video observers have more time than divers to discriminate among species in a given school.

378 The observation time required clearly depends on the technique used, and 379 additional time in the laboratory is necessary in the case of video, while more 380 time is spent in the field for UVC. In this study, the overall video observation 
381 time including the time spent underwater and the time spent at the laboratory, 382 was quite similar to UVC.

383 In the present study, the consequences of differences in the underwater 384 observation time were mitigated by the fact that the transect area was distinctly 385 delineated. For both S-type transects and UVC, the diver takes the time 386 required to capture, either by eye or by the camera, all of the fish that can be 387 seen at that moment within the transect area. Still, UVC requires more time underwater than S-type transects, because fish have to be identified and counted on-site. It is difficult to conclude which technique best estimates the

390 true abundance and species richness because as the observation time 391 underwater increases, the probability that a fish which is present in the vicinity 392 of the transect enters or leaves the delineated area also increases, so there is an increased possibility of counting the same fish twice and of seeing more 394 species, which is particularly true for mobile species. Indeed, the two 395 techniques provide distinct estimates of abundance and species richness. 396 However, the point of this study was to evaluate whether video transects 397 provide representative information about the fish assemblage, compared to a widely used technique such as UVC. It is also important to consider that for a given technique, observation time always increases with the in situ abundance 400 and diversity of fish and it will increase less for video than for UVC. The analysis 401 time per video transect also dramatically changes from temperate to tropical 402 regions (Langlois et al 2010).

403 The third point of comparison between these techniques deals with the 404 importance of the habitat type in fish detection. In our study, observations were 
405 done in several habitats with distinct characteristics, and the differences 406 between fish assemblages that we detected were not found to depend on 407 habitat complexity. Where some species and/or families were found in larger 408 abundances at some sites due to differences in habitat, the techniques used 409 were equally successful in the habitats surveyed. The differences that we 410 observed in fish abundance depended on the site for only one family 411 (Pomacentridae), as there was a great abundance of this family at one of the 412 sites. For the other families, the video and UVC techniques compared similarly 413 irrespective of the habitat considered.

414 Comparing the two video techniques, S-type transects yielded much greater 415 species richness and abundance than I-type transects. Conducting S-type 416 transects implies to delineate the surface area to be surveyed with a tape, but 417 permanent delineation enables to monitoring the same transects over years. 418 Because transects areas were delineated in this study, we avoided the issue of 419 estimating distance, which is an additional source of uncertainty for UVC and for 420 video techniques when stereo video is not used (Harvey et al. 2004). The I-type 421 transect was still tested because, as elevation and speed are standardized, it 422 could be used in other instances without having to delineate the transect area, 423 which allows for quicker monitoring. However, it appears that I-type video 424 transects may not capture all of the fish present in the area in a way that 425 enables subsequent identification and counting. Consequently, this type of 426 transect might be useful for monitoring particular species, but not the entire fish 427 assemblage.

428 Langlois et al. (2006) used another video technique, the baited remote 
429 underwater video (BRUV) in proximate sites within the same area (Signal Is.).

43014 species were observed among which 5 Serranidae, 4 Lethrinidae, 2

431 Carcharhinidae and 3 Acanthuridae. In this study, the corresponding numbers

432 of species observed were: i) for Serranidae, 5 species in videos versus 6 in

433 UVC, ii) for Lethrinidae, 3 in videos versus 1 in UVC, iii) for Carcharhinidae, 1 in

434 videos versus 0 in UVC, and iv) for Acanthuridae, 6 species in both videos and

435 UVC. The number of carnivorous species observed in video and UVC was

436 larger in our study, as additional species belonging to other families were seen.

437 Abundances observed in BRUV cannot be quantitatively compared to the 438 estimates obtained in the present study, as they are calculated in a different 439 way. The number of observations in Langlois et al. (2006) was smaller than in 440 this study, therefore species numbers cannot be directly compared. 441 Nevertheless, the results suggest that the presence of divers underwater 442 influences fish observation, particularly for key fished species.

443 Overall, our results demonstrate the relevance of the HD video technique 444 used here and of S-type transects for conducting monitoring of fish 445 assemblages and habitat.

4.2. Advantages and shortcomings of the techniques in terms of logistics

448 The differences between techniques mainly pertain to the diving time and 449 level of expertise of the diver that are required (Table 5). With respect to human resources, UVC requires at least one fish expert diver in the field, while a video 451 transect requires a single diver who does not necessarily need to be a fish 452 expert. As security regulations often require two divers underwater, and one at 
453 the surface, if two cameras are available, the number of observations can be 454 doubled using video. At the laboratory, UVC and video data can be input by a

455 single person. Videos were preferably analyzed by two persons, one of whom was a fish expert, but because the capacity for both species identification and counting from moving images increased during this process, a single person became perfectly able to do the work alone. Building the capacity for image analysis required some training, which was relatively quick when the analysis was conducted together with fish experts.

With respect to expertise, video transects can be conducted by any diver once they are trained to use the camera, which is quite easy, and a given video transect can be analyzed for both fish and habitat. In contrast, UVC transects require expert divers. At least one diver has to be able to identify fish species, and two are often required in coral reef ecosystems when all fish species are counted, as was the case in this study. UVC transects are generally run twice, one for fish, one for habitat.

With regard to the time taken for a given transect, I-type transects and S-type transects take on average $4 \mathrm{~min}$ and $30 \mathrm{~s}$ and $10 \mathrm{~min}$, respectively, in the field. At the laboratory, image analysis lasted from $45 \mathrm{~min}$ to $1 \mathrm{hr}$ and $30 \mathrm{~min}$ in the present study, depending on fish abundance and diversity. In the field, a UVC takes between 45 and $60 \mathrm{~min}$. At the laboratory, data input and validation require 10 to 15 min per transect. Therefore, S-type video transects and UVC are comparable in terms of the overall time required per transect. In terms of the time required for image analysis, our findings differ from those of previous investigators such as Francour et al. (1999), Cappo et al. (2003) and Stobart et 
al. (2007) who found that image analysis was the limiting factor for videos in the case of BRUV. This is probably due to the fact that image analysis is greatly facilitated with HD. In this case, it is also of note that the duration of a video transect conducted by a diver is shorter than that of a BRUV (10 min versus 30 min from Stobart et al. (2007) and Langlois et al. (2006)).

To summarize the advantages and shortcomings of the techniques used for observing fish assemblages (Table 6), UVC is a widely used technique, with experts around the world, but all species are not systematically identified by this technique in highly diversified ecosystems such as coral reefs. Indeed, many monitoring programs either require only information for some species or species groups, e.g., target species, or do not collect information at the species level, see e.g., the protocols recommended by the Global Coral Reef Monitoring Network (Hill and Wilkinson 2004). In addition, UVC only require data input after field work, unlike video-based techniques which require further image analysis. In our study, UVC led to the detection of significantly more fish individuals and fish species than video monitoring. The first advantage of video is that it does not require an expert in fish identification in the field, and hence, a nonspecialist diver can operate the camera. Second, video reduces the time spent underwater, allowing for more observations to be conducted. Less time in the field implies lower field costs, which are always larger than laboratory costs.

497 Third, habitat information is collected at the same time as fish information with 498 video. Fourth, video images may be archived, and they may be analyzed by several persons, thus limiting potential observer effects, which are sometimes a shortcoming of UVC (Preuss et al. 2009). Finally, video may also be analyzed 
501 for other purposes, e.g., for habitat or for a subset of species of interest.

502

503

504 From this study, we thus conclude that HD video is a technique that is worth 505 considering for observing and/or monitoring fish assemblages in highly 506 diversified ecosystems such as coral reefs. Our results for habitat observations 507 were not presented per transect, and further study is needed to evaluate the 508 efficiency of this technique for habitat monitoring, but the image analyses that 509 we carried out have already shown that habitat characterization is easier than

510 fish identification and abundance estimation. Using the MSA approach

511 described in this paper, it took at most 10 min to analyze a single transect for 512 habitat (Pelletier et al., unpubl. data).

513 Standard video was not considered in this study because the extra cost incurred

514 by using HD video compared to standard video is marginal in light of the overall 515 cost of conducting underwater observations, whether they are visual or video-

516 based. The main point of this study was to compare HD video to UVC which are 517 currently the most widely used technique for observing fish assemblages. It appears that HD video might constitute an interesting alternative to UVC when

519 these cannot be implemented, e.g., when no fish expert is available in the field.

520 Additionally, relying on several kinds of observation for monitoring is always

521 desirable (Willis et al. 2000; Cappo et al. 2004). However, both techniques 522 share a common disadvantage, namely the presence of divers underwater 523 (Table 6). Divers are known to disturb fish, particularly in fished areas (see

524 references in Stobart et al. 2007), where fish behavior differs from behavior in 
525 MPA, and this is a potential source of bias for assessing the effects of MPA on

526 fish assemblages. An additional shortcoming of these diving-based techniques

527 lies in the limited range of depth that can be investigated and the number of

528 observations that can be conducted per diver. Therefore, investigating

529 techniques that do not require the presence of divers underwater is a promising

530 alternative. Remotely operated video stations have been used for this purpose

531 (Watson et al. 2005, 2007; Willis et al. 2000, Willis and Babcock 2000, Westera

532 et al. 2003) and are increasingly envisaged as a monitoring tool for MPAs

533 (Pelletier et al. 2009; Stobart et al. 2007). These might be an interesting

534 complement to UVC, for instance, BRUV is now widely used in Australia and

535 New Zealand (Willis and Babcock 2000; Willis et al. 2000, Harvey et al. 2004)

536 and in the Mediterranean (Stobart et al. 2007). Using BRUV, a large number of

537 species have been observed in coral reef ecosystems (Cappo et al. 2007) and

538 in other contexts (Stobart et al. 2007), and observations can be carried out in

539 deep areas (Cappo et al. 2007). Other techniques for marine ecosystem

540 monitoring are also currently under development, and we will concentrate on

541 these in future studies.

542

543 Acknowledgements

544 We thank Tim Langlois and an anonymous reviewer for their numerous and

545 constructive comments on two earlier versions of this paper. This work was

546 made possible through funding of the ZONECO program of the New Caledonia

547 government and of the Coral Reef Initiative for the South Pacific program of the 548 French Agency for Development. 


\section{References}

551 Barans, C.A., Bortone, S.A., 1983. The visual assessment of fish populations in 552 the southeastern United States: 1982 Workshop. Technical Report 1 (SC553 SG-TR-01-83), South Carolina Grant Consortium, Charleston.

554 Bortone, S.A., Samoilys, M.A., Francour, P., 2000. Fish and macroinvertebrate 555 evaluation. In: Seaman Jr., W. (Ed.), Artificial Reef Evaluation with 556 application to Natural Marine Habitats. CRC Press, Boca Raton, pp. 127 557164.

558 Cappo M.C., Speare, P.J., Deat'h, G., 2007. Inter-reef vertebrate communities 559 of the Great Barrier Reef Marine Park determined by baited remote 560 underwater video stations. Mar. Ecol. Progr. Ser. 350, 209-221.

561 Cappo M.C., Speare, P.J., Deat'h, G., 2004. Comparison of baited remote 562 underwater video stations (BRUVS) and prawn (shrimp) trawls for 563 assessments of fish biodiversity in inter-reefal areas of the Great Barrier Reef 564 Marine Park. J. Exp. Mar. Biol. Ecol. 302, 123-152.

565 Cappo, M.C., Harvey, E.S, Malcolm, H.A., Speare, P.J., 2003. Potential of video 566 techniques to design and monitor diversity, abundance and size of fish in 567 studies of Marine Protected Areas. In: Beumer, J.P., Grant, A., Smith, D.C. 568 (Eds), Aquatic Protected Areas - what works best and how do we know? 569 World Congress on Aquatic Protected Areas Proceedings, Cairns, Australia, $570 \quad$ August 2002. Australian Society of Fish Biology, pp. 455-464.

571 Cappo, M.C., Brown, I., 1996. Evaluation of sampling methods for reef fish 572 populations of commercial and recreational interest, Technical Report No. 6, 
574 Clua, E., Legendre, P., Vigliola, L., Magron, F., Kulbicki, M., Sarramegna, S., 575 Labrosse, P., Galzin, R., 2006. Medium scale approach (MSA) for improved 576 assessment of coral reef fish habitat. J. Exp. Mar. Biol. Ecol. 333, 219-230.

577 Connell, J.H., 1978. Diversity in tropical rain forests and coral reefs. Science $578 \quad 199,1302-1310$.

579 Francour, P., Liret, C., Harvey, E., 1999. Comparison of fish abundance 580 estimates made by remote underwater video and visual counts. Natur. Sicil. $581 \quad 23,155-168$.

582 Harmelin-Vivien, M.L., Harmelin, J.G., Chauvet, C., Duval, C., Galzin, R., 583 Lejeune, P., Barnabé, G., Blanc, F., Chevalier, R., Duclerc J., Lasserre, G., 584 1985. Evaluation visuelle des peuplements et populations de poissons: 585 méthodes et problèmes. Rev. Ecol. (Terre Vie) 40, 467-539.

586 Harmelin-Vivien, M.L., Francour, P., 1992. Trawling or Visual Censuses 587 Methodological Bias in the Assessment of Fish Populations in Seagrass 588 Beds. Mar. Ecol. Pub. Sta. Zool. Napoli I 13, 41-51.

589 Harvey, E.S., Goetze, J., McLaren, B., Langlois, T., Shortis, M.R. 2010. 590 Influence of Range, Angle of View, Image Resolution and Image 591 Compression on Underwater Stereo-Video Measurements: High-Definition 592 and Broadcast-Resolution Video Cameras Compared. Marine Technology 593 Society Journal 44, 75-85.

594 Harvey, E., Fletcher, D., Shortis, M. R., Kendrick, G. A., 2004. A comparison of 595 underwater visual distance estimates made by scuba divers and a stereo596 video system: implications for underwater visual census of reef fish 
abundance. Mar. Freshw. Res. 55(6), 573-580.

598 Hill, J., Wilkinson, C., 2004. Methods for ecological monitoring of coral reefs.

$599 \quad$ Australian Institute of Marine Science, Townsville, Australia.

600 Kulbicki, M., 1998. How the acquired behaviour of commercial reef fishes may

601 influence the results obtained from visual censuses. J. Exp. Mar. Biol. Ecol. $602 \quad 222,11-30$.

603 Langlois, T.J., Harvey, E.S., Fitzpatrick, B., Meeuwig, J.J., Shedrawi, G., 604 Watson, D. L., 2010. Cost-efficient sampling of fish assemblages: 605 comparison of baited video stations and diver video transects. Aquat. Biol. 6069 9, 155-168.

607 Langlois, T.J., Chabanet, P., Pelletier, D., Harvey, E., 2006. Baited underwater 608 video for assessing reef fish populations in marine reserves. Sec. South Pac. $609 \quad$ Comm. Fish. Newsletter 118, 53-56.

610 Michalopoulos, C., Auster, P.J., Malatesta, R.J., 1992. A comparison of transect 611 and species time counts for assessing faunal abundance from video surveys. 612 Mar. Tech. Soc. J. 26 (4), 27-31.

613 Pelletier, D., Leleu, K., Mou-Tham, G., Hervé, G., Guilpart, N., Guillemot, N., 614 Chabanet, P., 2009. Monitoring biodiversity and resources in Marine 615 Protected Areas (MPA) using high definition video systems. International 616 Congress on Marine Protected Areas (IMPAC2), Washington, 19-24th May. 617 http://www2.cedarcrest.edu/imcc/Program_Abstracts/data/20090523.html\#70 $618 \quad 807$.

619 Potts, G.W., Wood, J.W., Edwards, J.M., 1987. Scuba diver operated low-light620 level video system for use in underwater research and survey. J. Mar. Biol. 
622 Preuss, B., Pelletier, D., Wantiez, L., Letourneur, Y., Sarramégna, S., Kulbicki,

623 M. Galzin, R., Ferraris, J., 2009. Considering multiple species attributes to 624 understand the effects of successive changes in protection status on a coral 625 reef fish assemblage. ICES J. Mar. Sci. 66, 170-179.

626 Ray, C.G., 1988. Ecological diversity in coastal zones and oceans. In: Wilson

627 E.O. (Ed.), Biodiversity, National Academic Press, Washington DC.

628 Samoilys, M., 1997. Underwater visual census surveys. In: Samoilys, M. (Ed.), 629 Manual for Assessing Fish Stocks on Pacific Coral Reefs, Department of $630 \quad$ Primary Industries, Townsville, Australia.

631 Samoilys MA, Carlos G. 2000. Determining methods of underwater visual 632 census for estimating the abundance of coral reef fishes. Env. Biol. Fish. 57, $633 \quad 289-304$.

634 Stewart, B.D., Beukers, J.S., 2000. Baited technique improves censuses of 635 cryptic fish in complex habitats. Mar. Ecol. Progr. Ser. 197, 259-272.

636 Stobart, B., García-Charton, J.A., Espejo, C., Rochel, E., Goñi, R., Renoñes, 637 O., Herrero, A., Crec'hriou, R., Polti, S., Marcos, C., Planes, S., Perez638 Ruzafa, A., 2007. A baited underwater video technique to assess shallow639 water Mediterranean fish assemblages: Methodological evaluation. J. Exp. $640 \quad$ Mar. Biol. Ecol. 345, 158-174.

641 Tessier, E., Chabanet, P., Pothin, K., Soria, M., Lasserre, G., 2005. Visual 642 census of tropical fish assemblages on artificial reef: slate versus video 643 recording techniques. J. Exp. Mar. Biol. Ecol. 315(1), 17-30.

644 Tipping, M.J., 1994. Measuring fish by video image processing. Progr. Fish 
Cult. 56, 299-300.

646 Watson, D.L., Harvey, E.S., Kendrick, G.A., Nardi, K., Anderson, M.J., 2007.

647 Protection from fishing alters the species composition of fish assemblages in

648 a temperate-tropical transition zone. Mar. Biol. 152, 1197-1206.

649 Watson, D.L., Harvey, E.S., Anderson, M.J., Kendrick, G.A., 2005. A 650 comparison of temperate reef fish assemblages recorded by three 651 underwater stereo-video techniques. Mar. Biol. 148, 415-425.

652

Watson, R.A., Carlos, G.M., Samoilys, M.A., 1995. Bias introduced by the nonrandom movement of fish in visual transect surveys. Ecol. Modell. 77, 205214.

655

Westera, M., Lavery, P., Hyndes, G., 2003. Differences in recreationally 656 targeted fishes between protected and fished areas of a coral reef marine park. J. Exp. Mar. Biol. Ecol. 294, 145-168.

658

Wilkinson, C., 2004. Status of coral reefs of the world. C. Wilkinson (Ed.), Australian International Marine Sciences, Townsville, Australia.

660

Willis, T.J., 2001. Visual census methods underestimate density and diversity of 661 cryptic reef fishes. J. Fish Biol. 59, 1401-1408.

662

Willis, T.J., Babcock, R.C., 2000. A baited underwater video system for the 663 determination of relative density of carnivorous reef fish. Mar. Freshw. Res.

664 $51,755-763$.

665 Willis, T.J., Millar, R.B., Babcock, R.C., 2000. Detection of spatial variability in 666 relative density of fishes: comparison of visual census, angling and baited 667 underwater video, Mar. Ecol. Progr. Ser. 198, 249-260.

668 


\section{FIGURE CAPTIONS}

Fig. 1. Study area. Three sites (indicated by flags) were selected along the reef slope on the leeward side of the Signal Islet, located in the south-west lagoon of New Caledonia, South Pacific (insert). From North to South, the three sites are respectively S3, S1 and S2.

Fig. 2. Boxplots of species richness per transect (in number of species per $\mathrm{m}^{2}$ (top) and abundance density per transect (in number of individuals) per $\mathrm{m}^{2}$ (bottom) per video transect type and per timing (before/after) with respect to UVC transect. 'I' and 'S' respectively denote I-type and S-type video transects, i.e. straight and browsing transects (see § 2.1).For each boxplot, the thick line in the box corresponds to the median value; the lower and upper limits of the box correspond to the $25 \%$ and $75 \%$ percentiles of the data. The plot whiskers extend out from the box to the most extreme data point which is no more than 1.5 times the interquartile range from the box and all values are plotted.

Fig. 3. Boxplots of species richness per transect (in number of species per $\mathrm{m}^{2}$ (top) and abundance density per transect (in number of individuals) per $\mathrm{m}^{2}$ (bottom) per site and transect type. 'I', 'S' and 'V' respectively denote I-type, S-type and UVC transects. Itype and S-type respectively refer to straight and browsing transects (see § 2.1). For each boxplot, the thick line in the box corresponds to the median value; the lower and upper limits of the box correspond to the $25 \%$ and $75 \%$ percentiles of the data. The plot whiskers extend out from the box to the most extreme data point which is no more than 1.5 times the interquartile range from the box and all values are plotted.

Fig. 4. Average species number per transect (in number of species per $200 \mathrm{~m}^{2}$ ) for each family, for UVC (light grey) and for S-type video (dark grey) transects. 
Fig. 1.

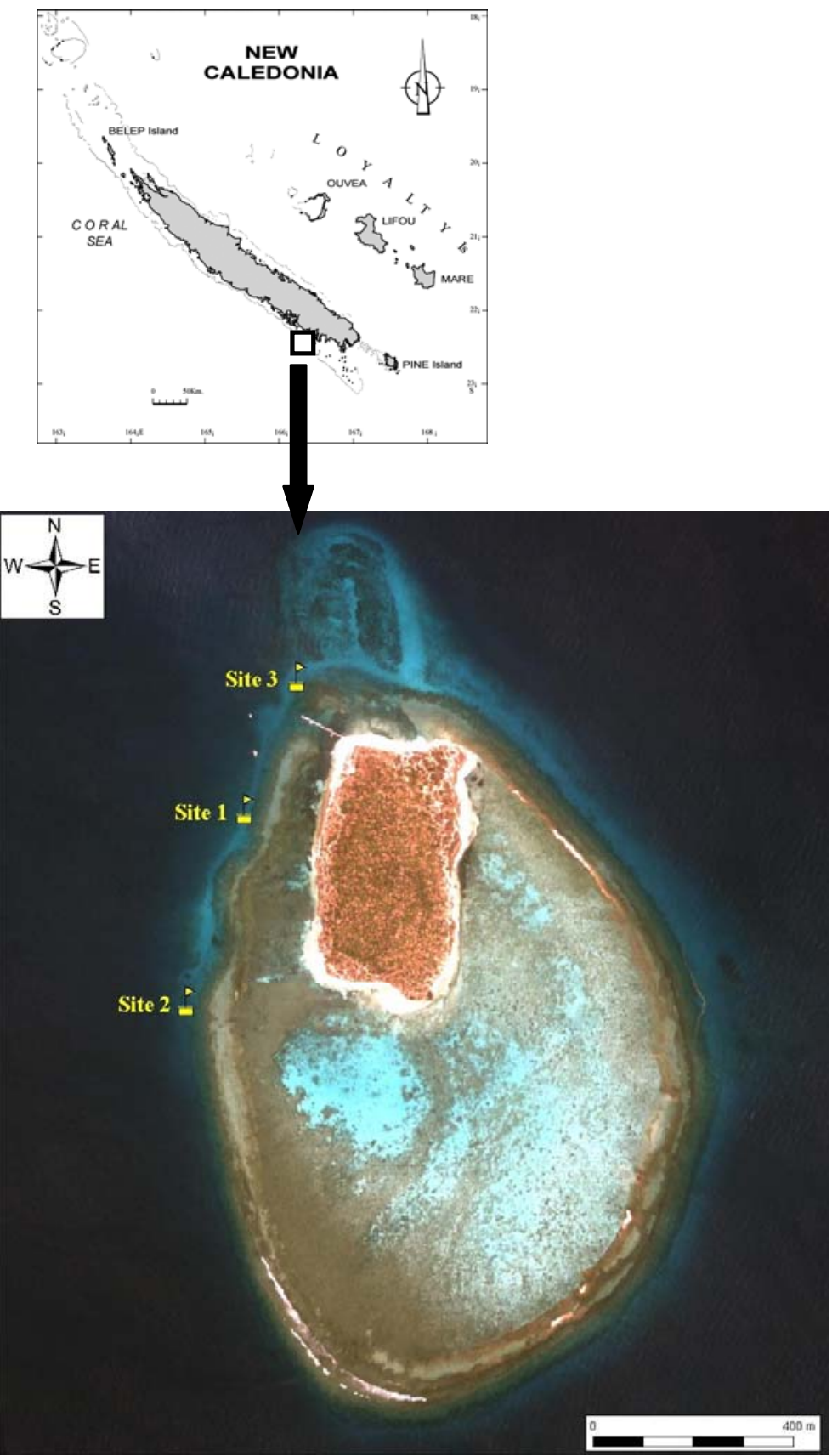



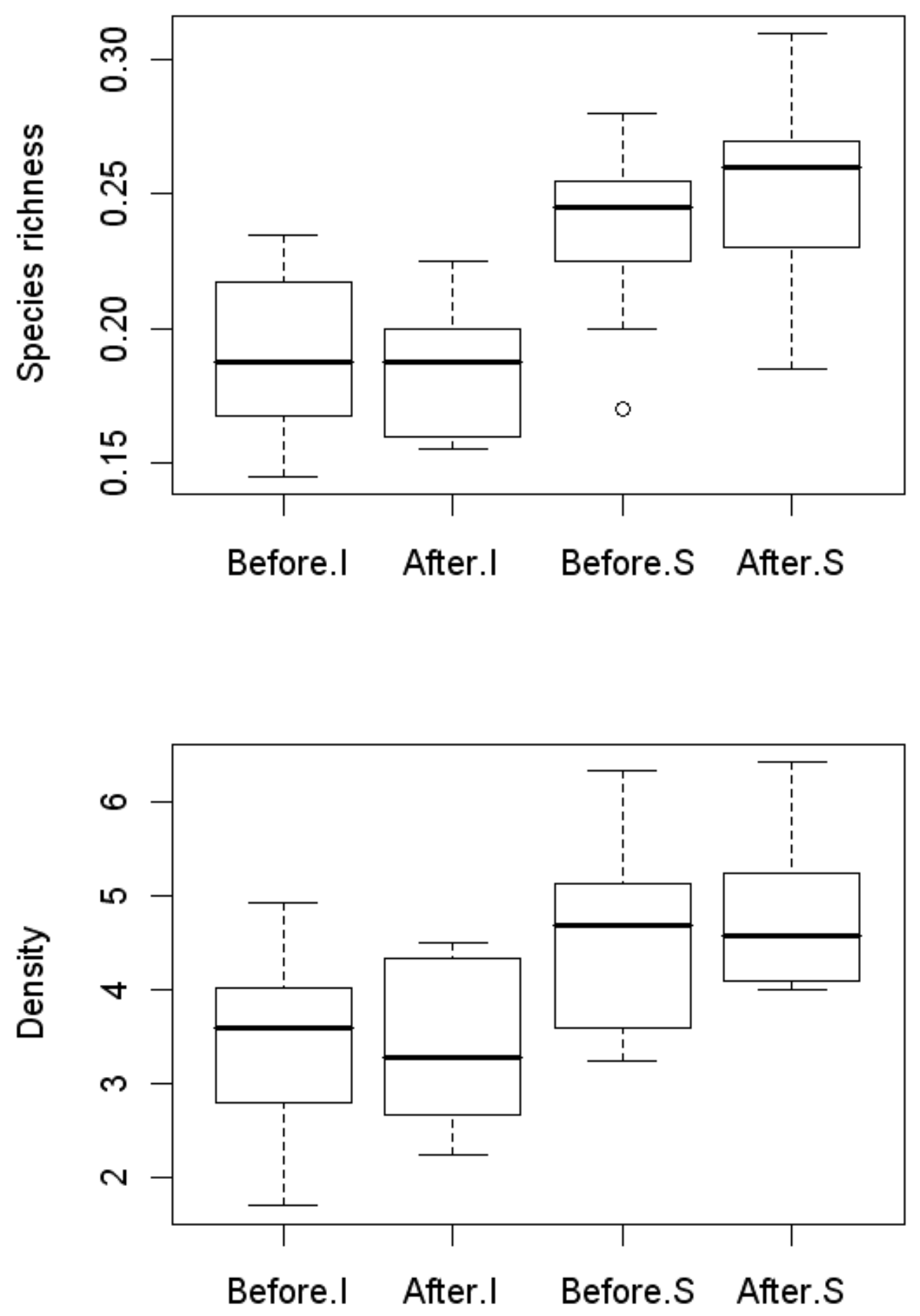
Fig. 3.

Pelletier et al.

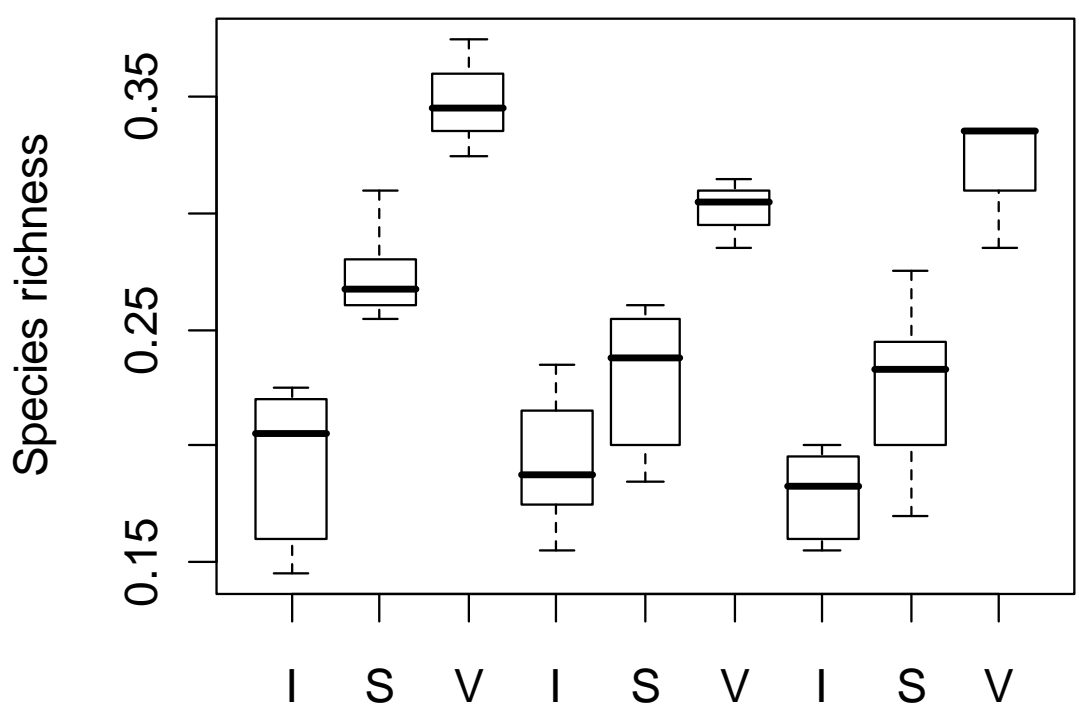

Site 1

Site 2

Site 3

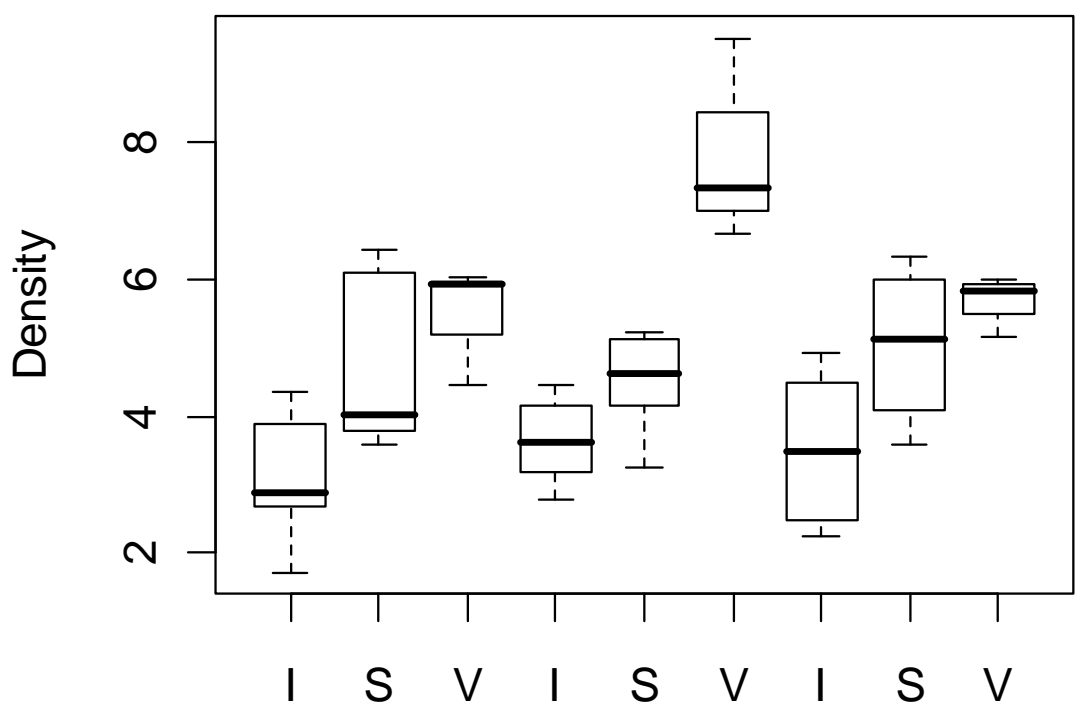

Site 1

Site 2

Site 3 


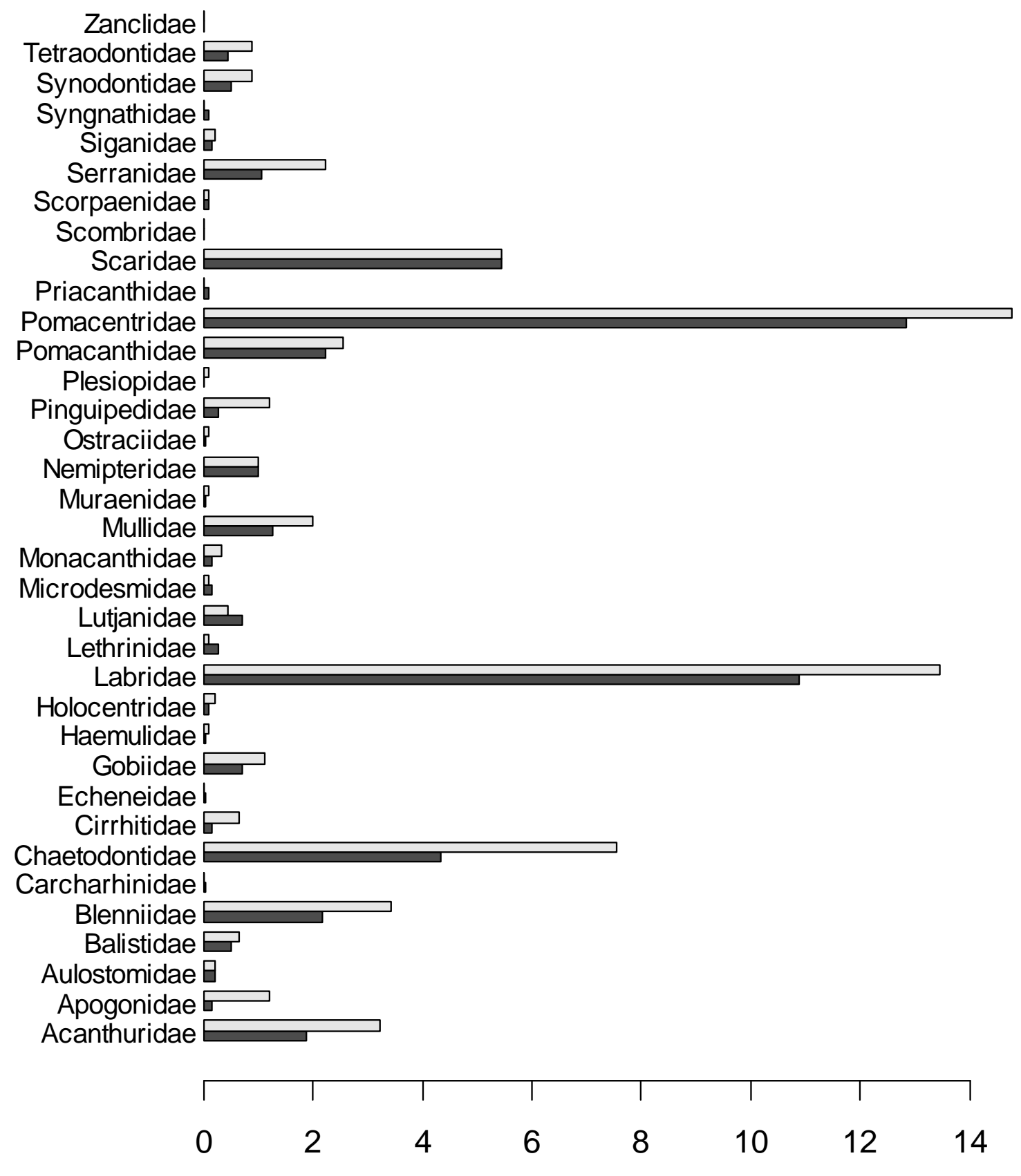

Fig. 4. Pelletier et al. 
3 Table 1. Per-cent composition of abiotic and biotic cover at the three study sites, as

4 recorded by the medium scale approach according to Clua et al. (2006). The per-cent

5 covers sum to $100 \%$ for both general cover and for living coral categories inside the

6 living hard coral component. Values larger than $10 \%$ are in bold.

\begin{tabular}{lrrr}
\hline \multicolumn{1}{l}{ Site 1} & \multicolumn{2}{l}{ Site 2} & \multicolumn{1}{c}{ Site 3} \\
General cover & & & \\
\hline Mud & 0.0 & 0.0 & 0.0 \\
Sand & $\mathbf{2 2 . 1}$ & 7.3 & $\mathbf{2 5 . 4}$ \\
Debris & $\mathbf{1 2 . 5}$ & $\mathbf{3 9 . 3}$ & $\mathbf{1 3 . 3}$ \\
Small boulder & 0.3 & 1.6 & 1.0 \\
Big boulder & 0.0 & 0.9 & 0.3 \\
Dead coral rock & $\mathbf{2 9 . 0}$ & $\mathbf{1 5 . 2}$ & $\mathbf{2 8 . 5}$ \\
Coral skeleton in place & 1.8 & 9.7 & 3.5 \\
Bleached coral & 0.0 & 1.8 & 0.8 \\
Living hard coral & $\mathbf{2 8 . 5}$ & $\mathbf{1 9 . 9}$ & $\mathbf{2 5 . 0}$ \\
Soft corals & 5.8 & 4.2 & 2.3 \\
\hline Composition of living hard coral & & & \\
\hline Encrusting & 9.1 & 5.8 & 9.9 \\
Massive & $\mathbf{5 9 . 6}$ & 9.8 & $\mathbf{2 7 . 4}$ \\
Digitated & 0.1 & 0.2 & 0.0 \\
Branched & $\mathbf{2 6 . 3}$ & $\mathbf{6 3 . 3}$ & $\mathbf{4 9 . 7}$ \\
Foliose & 0.0 & 0.0 & 0.0 \\
Tabular & 3.5 & $\mathbf{2 0 . 7}$ & $\mathbf{1 2 . 8}$ \\
Millepora. sp. & 1.4 & 0.2 & 0.2 \\
\hline
\end{tabular}


7 Table 2. Prediction of average species richness, abundance and number of

8 families per transect (per $200 \mathrm{~m}^{2}$ ) for each observation technique from a two-

9 way ANOVA with transect type and site factors. I-type and S-type refer to

10 straight and browsing transects, respectively (see Methods section). For each

11 technique, the average duration of an observation and the number of divers is

12 given in parentheses.

13

\begin{tabular}{lccc}
\hline Predicted metric & I-type video & S-type video & UVC \\
& transect (1 diver, 4 & transect (1 diver, & (1 expert diver, 45- \\
& $\min 30 \mathrm{~s})$ & $10 \mathrm{~min})$ & $60 \mathrm{~min})$ \\
\hline Species richness & 38.7 & 54.7 & 69.7 \\
Abundance & 612 & 932 & 1094 \\
Number of families & 12.5 & 15.1 & 18.4 \\
\hline
\end{tabular}

14 
15 Table 3. Number of occurrences (\# occur.), density and number of species (sp.

16 nb.) per family observed in the 18 S-type video transects and in the 9 UVC

17 transects (S-type refers to browsing transects). Total abundance is the number

18 of fish encountered over given types of transects. Mean abundance per family is

19 computed by first adding individuals per family per transect and then averaging

20 over the transects of a given type. It is expressed in number of individuals per

21 transect surface area (each transect has a surface area of $200 \mathrm{~m}^{2}$ ).

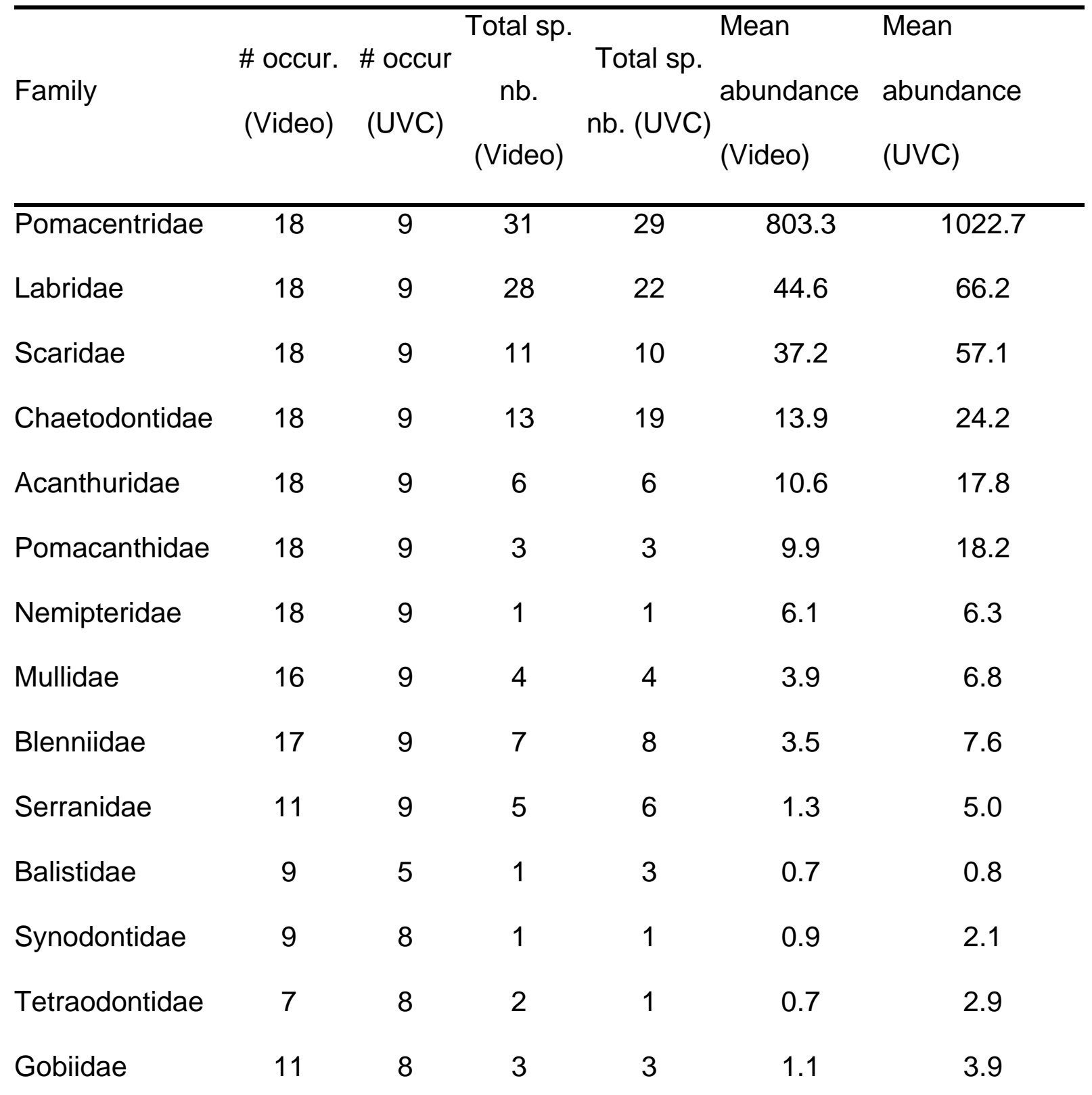


Table 3 (continued)

\begin{tabular}{|c|c|c|c|c|c|c|}
\hline Lutjanidae & 10 & 3 & 7 & 2 & 6.1 & 8.6 \\
\hline Penguipedidae & 4 & 8 & 2 & 2 & 0.5 & 4.7 \\
\hline Aulostomidae & 4 & 2 & 1 & 1 & 0.3 & 0.4 \\
\hline Siganidae & 3 & 2 & 1 & 2 & 0.4 & 0.3 \\
\hline Lethrinidae & 4 & 1 & 3 & 1 & 0.3 & 0.2 \\
\hline Monacanthidae & 3 & 3 & 1 & 1 & 0.3 & 0.9 \\
\hline Cirrhitidae & 3 & 6 & 1 & 1 & 0.2 & 1.3 \\
\hline Apogonidae & 2 & 7 & 2 & 4 & 0.3 & 6.7 \\
\hline Microdesmidae & 3 & 1 & 2 & 1 & 0.2 & 0.2 \\
\hline Haemulidae & 1 & 1 & 1 & 1 & 0.1 & 0.2 \\
\hline Scorpaenidae & 2 & 1 & 1 & 1 & 0.1 & 0.1 \\
\hline Ostraciidae & 1 & 1 & 1 & 1 & 0.1 & 0.1 \\
\hline Syngnathidae & 2 & 0 & 1 & 0 & 0.1 & 0.1 \\
\hline Priacanthidae & 2 & 0 & 1 & 0 & 0.1 & 0 \\
\hline Holocentridae & 2 & 2 & 2 & 2 & 0.1 & 0.3 \\
\hline Muraenidae & 1 & 1 & 1 & 1 & 0.1 & 0.1 \\
\hline Zanclidae & 1 & 0 & 1 & 0 & 0.03 & 0 \\
\hline Carcharhinidae & 1 & 0 & 1 & 0 & 0.06 & 0 \\
\hline Scombridae & 1 & 0 & 1 & 0 & 0.007 & 0 \\
\hline Echeneidae & 1 & 0 & 1 & 0 & 0.06 & 0 \\
\hline Plesiopidae & 0 & 1 & 0 & 1 & 0 & 0.2 \\
\hline
\end{tabular}


24 Table 4. ANOVA results for abundance per family for families frequently

25 encountered (in more than $75 \%$ of S-type video transects and in all UVC

26 transects) (S-type refers to browsing transects). Model assumptions were not

27 met for other families. 'Type' stands for transect type effect while 'Site' stands

28 for site effect. The effect linked to site 1 has no p-value attached as the 29 coefficient is set to 0 by contrast options in the ANOVA model.

Family

Model significance

Significant effects

Direction of effects and model predictions of abundance

More fish in UVC $(p<0.01)$

$R^{2}=0.48, F(8,36)=6.2\left(p<6.10^{-5}\right) \quad$ More fish at site 2 in UVC

Pomacentridae Type $\left(p<5.10^{-6}\right)$ \& Site*type $(p<0.05)$

$(p<0.03)$

Labridae

Scaridae

Chaetodontidae

$$
R^{2}=0.44, F(8,36)=5.3\left(p<2.10^{-4}\right)
$$

Type $\left(p<5.10^{-6}\right)$

Acanthuridae
$R^{2}=0.78, F(8,36)=6.2\left(p<8.10^{-10}\right)$

Type $\left(p<2.10^{-11}\right) \&$ Site $\left(p<2.10^{-4}\right)$

$R^{2}=0.69, F(8,36)=13.5\left(p<9.10^{-9}\right)$

Type $\left(p<7.10^{-5}\right) \&$ Site $\left(p<7.10^{-10}\right)$

abundance

More fish in UVC $(p<0.01)$

Video detects $72 \%$ of UVC abundance

More fish in UVC $\left(p<1.2 .10^{-4}\right)$ 


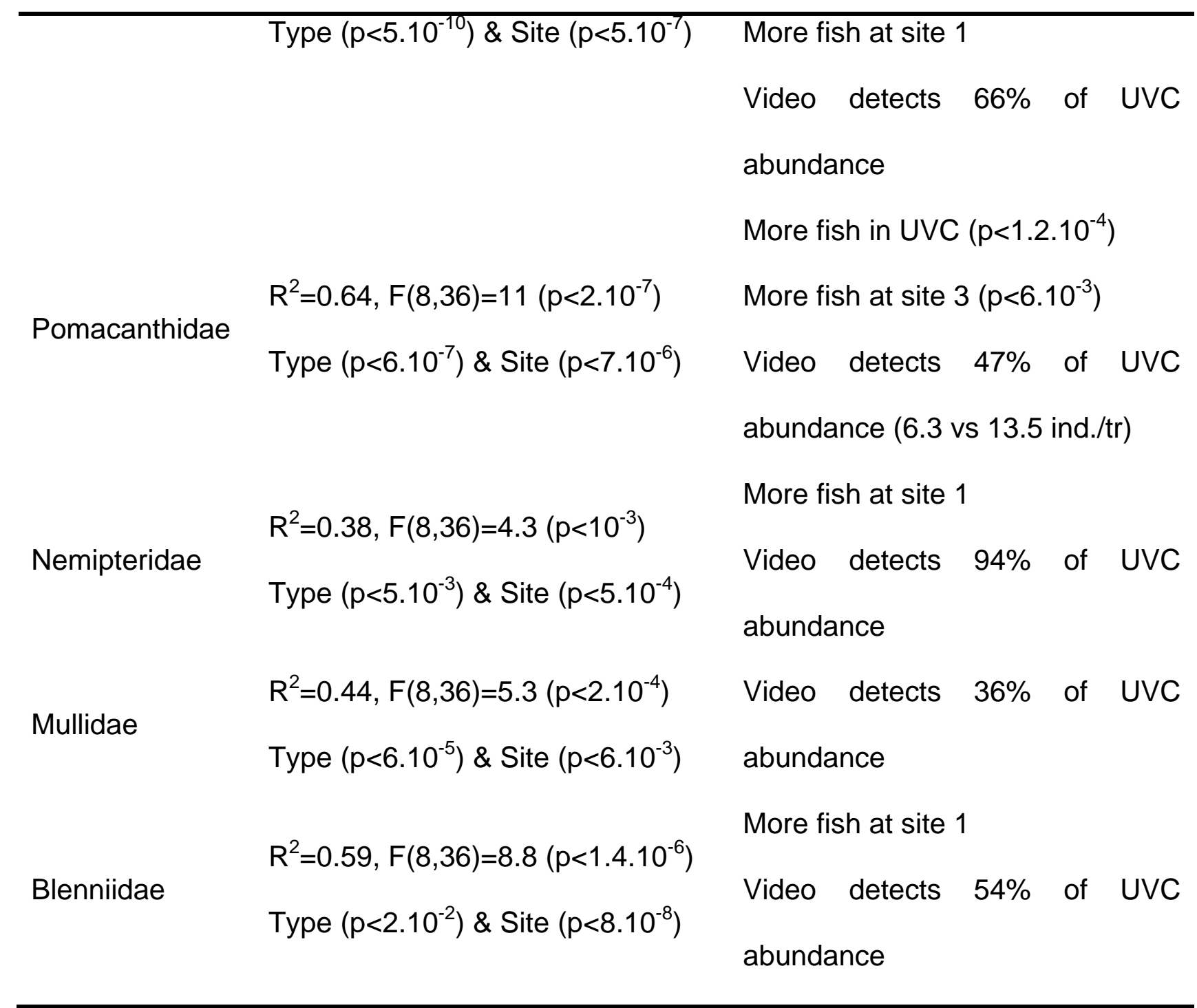


32 Table 5. Observation costs for the techniques used in this study. Observation

33 time for fish corresponds to the identification of all species. For habitat, it

34 corresponds to the implementation of the MSA approach (see Methods).

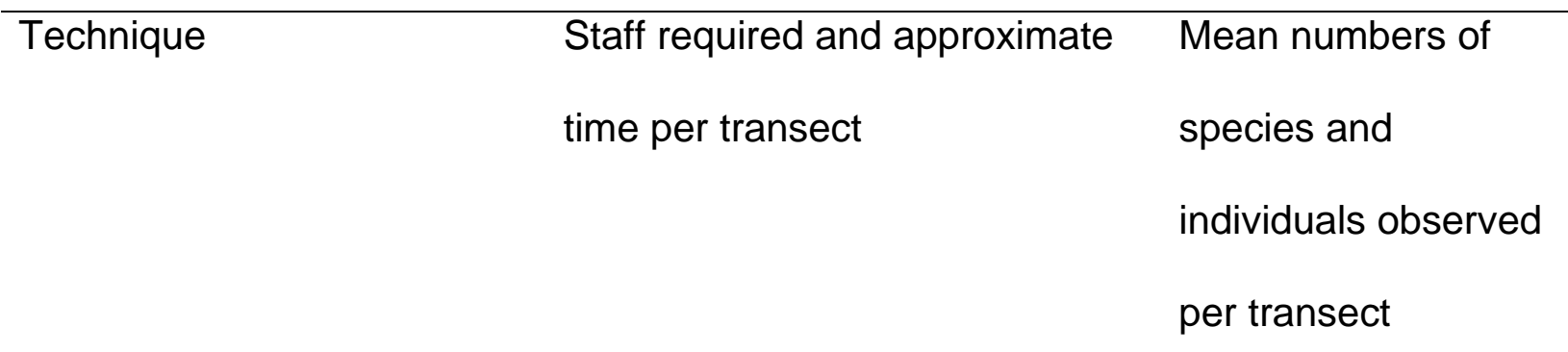

UVC transect In the field 1 or 2 fish expert divers

45 to $60 \mathrm{~min}$ (fish)

$10 \min$ (habitat)

64.6 species

At the office 1 person to input data

1266 individuals

10 to $15 \min$

\begin{tabular}{|c|c|c|c|}
\hline \multirow{5}{*}{$\begin{array}{l}\text { S-type video } \\
\text { transect }\end{array}$} & In the field & 1 non-specialist diver & \multirow{5}{*}{$\begin{array}{l}48.6 \text { species } \\
947 \text { individuals }\end{array}$} \\
\hline & & $10 \mathrm{~min}$ & \\
\hline & \multirow[t]{3}{*}{ At the office } & 1 fish expert & \\
\hline & & $45 \mathrm{~min}$ to $1 \mathrm{hr}$ and $30 \mathrm{~min}$ (fish) & \\
\hline & & 10 min (habitat) & \\
\hline \multirow{5}{*}{$\begin{array}{l}\text { I-type video } \\
\text { transect }\end{array}$} & \multirow[t]{2}{*}{ In the field } & 1 non-specialist diver & \\
\hline & & $4 \min 30 s$ & 37.67 species \\
\hline & \multirow[t]{3}{*}{ At the office } & 1 fish expert & \multirow[t]{3}{*}{681.3 individuals } \\
\hline & & $30 \mathrm{~min}$ to $1 \mathrm{hr}$ (fish) & \\
\hline & & $10 \min$ (habitat) & \\
\hline
\end{tabular}


37 Table 6. Advantages and disadvantages of the techniques used for observing

38 fish assemblages in reef ecosystems.

\begin{tabular}{lll}
\hline Technique & Advantages & Disadvantages \\
\hline UVC & Widely used & Requires qualified divers \\
Samoilys & Most complete observation of fish assemblage & Diver effect on fish \\
$(1998)$ & Limited additional time at the office required & Observer effect on counts \\
Harmelin- & & Additional field effort \\
Vivien et al. & needed for habitat \\
$(1985)$ & information \\
& & Limited diving time and \\
& & maximum depth
\end{tabular}

\begin{tabular}{lll}
\hline HD Video & Relatively complete observation of fish & Diver effect on fish \\
transects & assemblage & Takes additional time for \\
& Reduced underwater observation time & image analysis \\
& Simultaneous habitat information & Limited diving time and \\
& Limited observer effect (multiple image & depth \\
& analysis) & \\
\hline Baited & Images are archived & \\
Remotely & In general relatively complete observation of & Uncertainty about the bait \\
Operated & species & plume \\
Video (Willis & No diver effect on fish & Takes additional time for \\
and Babcock & No depth limitation & image analysis \\
2000; Cappo & Size estimation (if stereo video) &
\end{tabular}


et al. 2003; Images are archived

$2004 ; 2006)$

39

40

41 